\title{
CUESTIONES MUNICIPALES EN 1843 Y 1943
}

Se ha ponderado la dificultad de determinar científicamente la naturaleza y esencia jurídica del Municipio, y se ha dicho que la razón de la misma está en la génesis de nuestra esencia y en el modo de concebirlo y considerarlo en la historia (I): por eso cuando se nos ha interesado en expresar en unas cuartillas un recuerdo a los administrativistas de 1843 hemos pensado que un modo de rendir un tributo de admiración a la esencia de los cultos escritores de dicha fecha sería recordar lo que uno de ellos, José Posada de Herrera, en el año I843, en que publicó su obra "Lecciones de Administración" expresa con relación a distintos extremos que hoy se discuten en nuestra moderna literatura jurídica con respecto al Municipio, sin que este trabajo busque en otras publicaciones de dicho autor la confirmación de nuestras afirmaciones por la limitada extensión a que deben reducirse $\mathbf{y}$ prescindiendo por completo del estudio del hombre de gobierno en la historia de nuestra política.

Para mostrar su agudeza de ingenio y profundidad de pensamiento vamos a transcribir unos conceptos con respecto al $\mathrm{Mu}$ nicipio, expuestos en su citada obra, y a continuación analizaremos distintos textos de la misma, viendo cómo se intuían algunos pensamientos que forman hoy distintas construcciones de nuestra doctrina jurídica municipalista.

Dice Posada de Herrera: "Vamos a entrar en el examen de una materia muy importante por su naturaleza, y más importante todavía por el carácter que nuestras divisiones políticas han dado a todas las cuestiones que tienen con ella relación. Al oír las pa-

(1) Von Stcin "La Scienza della publica amministrazione". Torino 1897, pág. 205. 
labras Ayuntamientos, libertades municipales, poder municipal, se exaltan muchas susceptibilidades, unas temerosas de tales voces y entusiasmadas otras con los recuerdos que despiertan, pero todas dándoles significaciones vagas y de aplicación peligrosa. No pueden tener la fuerza que tuvieron algún día, y todos están conformes; pero el error en las voces produce confusión y mala inteligencia en las ideas.

Se dice, por ejemplo, poder municipal; ¿y qué significa esta palabra? ¿Es, por ventura, el poder de las municipalidades un poder cualquiera de los que reconoce la Constitución como poder del Estado? No es un poder del Estado, pero al mismo tiempo debe entrar a formar parte de él. Por poder municipal entiendo yo aquellas atribuciones que corresponden a estas corporaciones populares que llamamos Ayuntamientos para arreglar sus intereses particulares y para darse ciertas reglas en aquellos puntos que sólo a ellos interesan. Es decir, que así como el individuo tiene fuerzas que le son propias y otras que no lo son, derechos que le pertenecen y otros que no, así en las municipalidades hay fuerzas que les son propias y derechos que le son inher'entes. En este sentido no habría inconveniente en usar de la palabra poder municipal. Las municipalidades son la primera base de la organización social. Antes de que hubiera Gobierno central ya existian, y los pueblos buscaban en ellas el principio de su asociación, la defensa contra el más fuerte. Así como la nación tiene intereses generales que comprenden toda lá extensión del territorio, así también la provincia tiene intereses provinciales y la municipalidad intereses locales, y así como los intereses de la nación deben estar representados y debe haber quien vele por ellos, de la misma manera los intereses de la municipalidad deben estar representados y tener sus defensores. En un Gobierno representativo es principio reconocido que todos los derechos, todos los intereses, por pequeños que sean, dentro de la sociedad, deben tener su representación, y si faltando esta circunstancia se rompiese cualquiera de los eslabones que constituyen esta cadena social, sería imperfecta y defectuosa la organización del Estado, resultante de principios contradictorios. En todas partes los intereses locales deben tener sus representantes, nombrados con arreglo a las leyes del país, y deben tenerlos, sobre todo en España, donde las instituciones estuvieron tan arraigadas y han producido frutos tan provechosos; ¿pero de qué manera se organiza esta representación 
de los intereses locales para que ella nos satisfaga completamente y no hiera, ni pueda menoscabar, los intereses de la sociedad? ¿De qué manera se ha de organizar esta pequeña sociedad de un pueblo o de todo el término que forma un Ayuntamiento para que los intereses individuales que están al lado de esta asociación no sean heridos y encuentren en las leyes, y en los magistrados que las apliquen, la protección necesaria? ¿De qué modo los intereses de esta asociación serán protegidos por los intereses de la sociedad en general y por los agentes que éstos representan? He aqui las dificultades que inmediatamente presenta este problema en su resolución. Un medio, sin embargo, hay muy sencillo, y que se ocurrirá, desde luego, al que quiera pensar poco y vencer pronto todas las dificultades. No faltará quien diga, cortando el nudo, ya que no puede desatarlo: puesto que estos intereses de asociación, de pueblo o distrito, de ayuntamiento, están amenazados, puestos que esta misma asociación puede amenazar los intereses individuales, intereses generales del país, destruyamos este derecho que le corresponde de representarse y de defenderse; encarguemos a la sociedad no sólo de la defensa de su propia seguridad, sino de la de todos los derechos individuales y particulares de la localidad: hagamos, en una palabra, que todo esté sujeto a la acción única, exclusiva del poder central. Pero a poco que se pare la reflexión sobre esta materia ocurre una pregunta: ¿ será justo sofocar así el interés de esta asociación particular y que la sociedad se constituya en juez árbitro de sus derechos? ¿Los agentes del poder central que representan la sociedad en masa, tendrían el conocimiento suficiente de la localidad y de sus intereses para dirigirlos y resolverlos con acierto? Es claro que no, y como por otra parte no tienen más que un interés muy secundario en la buena dirección de los puramente locales, no hay derecho alguno para que el poder central se arrogue la facultad de sujetar a su albedrio a los Ayuntamientos y fallar en todos los casos sobre la fortuna y derechos que representan. Se ve, pues, evidentemente que es necesario detener en cierto punto la acción del poder central y dejar desembarazada la del poder de la localidad. Pero se dirá que un Gobierno monárquico exige que el Jefe del Estado ejerza su autoridad en todos los puntos de la nación, y que estas asociaciones son una especie de repúblicas con la independencia en que se las quiere

12 constituir. Se dirá también: vosotros fraccionáis, desde luego, el 
cuerpo social, rompéis la unidad que debe enlazarlo, desde el príncipe hasta la última cabaña, unidad que es el elemento de su existencia y el principio de su vida. Si el interés de la Monarquía debiera consultarse solamente, yo diría entonces que las instituciones municipales eran su más fuerte apoyo, que para afirmar la Monarquía en las entrañas de la sociedad debian desarrollarse con arreglo a su indole y carácter, de que después me haré cargo, más bien que disponer que desde el poder central se atendiera a todos los intereses y derechos que a los pueblos en particular pertenecen. Ningún provecho se sacará de aumentar la fuerza del poder, ahogando para ello las influencias locales; antes bien, es necesario hacer que el interés de la sociedad en general y el interés local, sin ser dirigidos ambos por una misma mano, tengan una recíproca influencia, caminando a la par, sin entorpecerse en sus movimientos."

En la anterior transcripción hay un gran número de cuestiones referentes a la administración del Municipio, que hoy han sido dibujadas en construcciones jurídicas municipalistas; ya que no estudiemos todas, veamos algunas.

Una de ellas es la autarquía del Municipio. Esta construcción es obra del cultísimo Santi Romano (I) que, como afirma el profesor Cino Vitta (2), ha sido generalizada en la doctrina jurídica.

Sus principios fundamentales pueden expresarse en la forma siguiente: El Estado se presenta como el centro de un máximo ćrculo de intereses, en el cual están comprendidos círculos menores, que si bien pueden no rozar la esfera de la acción del Estado, a poco que adquieran cierta amplitud pueden tener con el mismo Estado puntos de interferencia; pero si prevalecen principios de una sana y razonable descentralización, se tiende a re conocer como verdaderos. sujetos de derecho a las comunidadés de personas que un proceso más o menos natural y espontáneo ha constituido por la identidad de intereses sociales, siendo por el ordenamiento jurídico considerado como intereses de dichos sujetos no obstante ser, al mismo tiempo, intereses del Estado. La capacidad que a los primeros se concede de proveerse por. sí mismos se designa con el nombre de autarquia, precisamente por

(1) Comme: "Primo trattato completo di diritto ammisistratiro italiano a cur de V. E. Orlando". Volume secondo. pág. 576.

(2) "Diritto amministrativo". Volume primo, pas. 123. 
la posibilidad que el Estado venga llamado a sustituirlos; por eso cuando falta esta posibilidad, como sucede tratándose de personas privadas, el nombre de autarquía no es adecuado, haciendo preciso cuando se trata de afirmar una limitación fundamental del Estado a favor de otras entidades. Autarquía es una capacidad sui generis que deriva de la renuncia del Estado al ejercicio de una actividad que es contenido natural de la esfera de las funciones del ente. Esta doctrina se encuentra intuída en el pensamiento de Posada de Herrera. Es característica de la autarquía la relación entre el Estado y el Municipio, cuya relación es afirmada por nuestro autor, es igualmente característica de la autarquía que los intereses del Municipio sean comunes ron los del Estado, y esto lo proclama con aquella frase de que el poder municipal no es un poder del Estado, pero al mismo tiempo debe entrar a formar parte de él, y es también característica de la autarquía la renuncia en el Gobierno de intereses del Municipio en favor de éste, y esto lo declara cuando dice que no es justo sofocar el interés del Municipio y constituir a la sociedad como árbitro de sus derechos. Pero no sólo se percibe en Posada de Herrera la figura de la autarquía del Municipio, sino que se distingue este concepto de la autarquía tal como ha sido diferenciada en la doctrina de nuestros días.

Así, el mismo Santi Romano (I) nos asegura que de la autarquía no puede hablarse para designar la posición del Estado miembro del Estado federal, puesto que la capacidad del primero a gobernarse y administrarse por sí no deriva de una limitación impuesta por el segundo; la facultad de gobernarse y administrarse tiene un origen independientemente del poder del Estado federal, lo que nos demuestra que tal independencia no presenta los extremos que son precisos para que surja el concepto de autarquia, y tal vez no seria impropia designarla con el nombre de autonomia.

Pues bien: en la doctrina de Posada de Herrera se percibe de qué modo con respecto al Municipio le adjudica una administración autárquica y le niega la conceptuación de la figura de autonomía; díganlo aquellas frases en las que manifiesta, refiriéndose al Municipio, que puede suceder que, una vez por omisión y otras por exceso, falte a sus deberes, y el Gobierno, que está encargado de vigilar por los intereses de la sociedad, de aten-

It (x) Ob. cit, parg. sps 
der a todos los individuos y procurar que éstos no sean atropellados; que estas corporaciones se contengan dentro de ciertos limites, afirmando que, si los Ayuntamientos abusan de las atribuciones que la ley les concede, el Gobierno podrá contener a estas corporaciones dentro de los límites de sus atribuciones respectivas.

Siguiendo el estudio de las relaciones entre la doctrina de Posada de Herrera y las modernas orientaciones científicas, vemos de qué manera coincide su doctrina en otra tesis, como es la mantenida por Otto Mayer (I), cuando sostiene que entre las personas morales que se encuentraṇ por debajo del Estado las más considerables son los Municipios, que se les denomina cuerpos de administración propia (Selbsterwaltrugsköper). Esta expresión parece conveniente para designar de una manera general una persona moral destinada a ocuparse por sí misma de una parte de la administración pública, por oposición con el Estado, que tiene la plenitud de esta administración, y añade: pero el cuerpo que se administra por sí propio es también objeto de la administración del Estado, como lo atestigua el poder de control que tiene el mismo Estado. Posada de Herrera sienta la doctrina que los Ayuntamientos no pueden ser absolutamente independientes en sus asuntos sin tener enlace ni relación con ninguna autoridad superior, diciendo en otro extremo que el Gobierno es el tutor de los pueblos y que debemos tener de él esta idea.

Para terminar el estudio comparativo del pensamiento de Posada de Herrera en 1843 y la doctrina de nuestro tiempo, vamos a examinar una cuestión tan controvertida como es la de! nombramiento de alcalde. Dice Orlando (2) que en el alcalde se concentra toda la capacidad activa del Municipio, constituyéndose en cabeza y órgano integral. Pero se encuentra en él la cualidad de funcionario del Gobierno, en este sentido ocupa el último grado en la jerarquía administrativa. Esta doble cualidad ha sembrado dudas en las legislaciones y en la ciencia respecto a los criterios para el nombramiento de este funcionario, pudiendo dividirse en tres grupos los sistemas y opiniones: elección exclusivamente confiada a los elementos locales, elección exclusivamente confiada al Gobierno central, elección mixta con intervención recíproca de ambas autoridades. Se refuta el siste-

(1) "Le droit administratif allemand". París; I96. T. IV, págs. 260 y 261.

(2) "Principii di diritto amministrativo". Firence, 1925. Pág. 233 
ma que hace del alcalde un funcionario burócrata de exclusiva confianza de la administración central, que contradice al objeto principal de su oficio, que es precisamente representar al Municipio, y contradice a la índole orgánica de las instituciones municipales, cuya representación ha sido constituida electivamente. Un sistema ecléctico parece a primera vista que satisface las cpuestas exigencias y responde mejor a la doble cualidad que el alcalde reviste. Tal es el sistema italiano de la ley de 1865 , que para los Municipios menores estuvo en vigor hasta el año 1896 , por el cual el alcalde se elegía por la autoridad central, pero entre los consejeros municipales, acatando su título representativo. Sin embargo, también contra esta tendencia se presentan objeciones graves y fundadas. En efecto, si el elegido gubernativamente es conforme a las indicaciones de la mayoría de los individuos que constituyen el Municipio, su intervención es inútil; si está disconforme, se originaría un gravísimo daño a la administración. Es de notar, finalmente, que el derecho de la autoridad central puede ser garantizado ejerciendo la tutela por medio de otras instituciones.

No puede ser más idéntico el criterio de Posada de Herrera. Dice así: Para sostener que los alcaldes deben elegirse por la $\mathrm{Co}-$ rona se forma este raciocinio: los alcaldes tienen dos clases de atribuciones: las unas como administradores de la municipalidad y representantes del pueblo para la administración y cuidado de sus intereses; las otras como agentes del Gobierno encargalos de vigilar el cumplimiento de las leyes y llevarlas a ejecución en ciertos casos; si pues el alcalde tiene estas dos consideraciones, claro es que debe haber dos clases de personas que tengan influencia en su nombramiento: el pueblo, porque representa sus intereses, y el Monarca o el poder ejecutivo, que también es representado por el alcalde. Es necesario combinar estos dos elementos y hacer que entrambos concurran a producir su nombramiento. Este argumento deslumbra a primera vista, pero a poco que se examine se ve que falta por su base. El alcalde tiene atribuciones que le son propias, que existen en el carácter, en la esencia de su magistratura, y son todas las que le corresponden como administrador de la municipalidad, como jefe del Ayuntamiento, encargado de la dirección de los negocios municipales; tiene otras atribuciones, que son todas las que el Gobierno le concede con la 16 ejecución de las leyes: las unas son tan esenciales en la persora 
del alcalde, que sin ellas no merecen este nombre ni tampoco ser indjviduo del Ayuntamiento; las otras son indiferentes y puramente ocasionales en la persona del alcalde y pudiera muy bien el Gobierno, así como se las concede, concederlas a otra cualquiera persona que tuviese por conveniente.

Gregorio de Pereda Ugarte 